\title{
MONITORING MOVEMENT AT MAKLI
}

\author{
R. Eppich ${ }^{1 *}$, K. A. Mahessar ${ }^{2}$, S. Nawaz ${ }^{2}$ \\ ${ }^{1}$ Escuela Técnica Superior de Arquitectura, Universidad Politécnica de Madrid - rr.eppich@alumnos.upm.es \\ ${ }^{2}$ Directorate General of Antiquities, Ministry of Culture, Tourism \& Antiquities, Government of Sindh - ayaz.kazi@hotmail.com, \\ antiq2011@hotmail.com
}

Commission II, WG II/8

KEY WORDS: Makli Hills, Thatta, Sindh, crack monitoring, subsurface settlement

\begin{abstract}
:
Monitoring the movement of historic structures on unstable geology is a critical part of conservation. Such documentation can be accomplished using a variety of techniques from close observation to highly accurate instrumentation. However, the monitoring of nearly a hundred structures with varying levels of significance over a large area with limited resources is challenging. This paper describes the approach, methodology, planning, and execution of the initial monitoring system for the historic mausoleums at Makli Hills, Thatta in Sindh (Pakistan). This World Heritage property, located along six kilometers of bluffs above an ancient branch of the Indus River contains the tombs of rulers, poets, and spiritual leaders spanning from the XIV ${ }^{\text {th }}$ to XVIII ${ }^{\text {th }}$ centuries. These tombs, built at the edge of eroding bluff, have been subjected to differential settlement leading to a number of past structural failures, serious cracks, deformations, and potential failures. The paper describes this important site, it's problems, and a methodology to balance the significance and the sheer number of monuments with risk and available budget.
\end{abstract}

\section{INTRODUCTION}

\subsection{Historic Monuments at Makli Hills, Thatta}

The World Heritage property, Historical Monuments at Makli, is a unique place, an ancient necropolis, yet full of life as it is home to 21 active shrines. This extensive site situated along 6 kilometers of bluffs above an old course of the Indus River and covers over 1,000 acres with 64 significant mausoleums and large tombs, canopies, extent domes, and between 500,000 and 1 million graves. It contains the remains of local and prominent families, spiritual leaders, and dynasty rulers spanning from the XIV th $^{\text {th }}$ XVIII ${ }^{\text {th }}$ centuries (Lari, 1997, Siddiqi, 1963, 1970, Khan, 1989). This extensive site is maintained by a new team managed by a full-time site manager and part-time staff under the supervision of the Department of Antiquities of Sindh. The team is busy as the site is facing a number of serious threats ranging from decades of insufficient maintenance, lack of conservation, heavy visitation, poor drainage, inadequate original materials, encroaching settlements, and wind-borne salts and sand (Qasim, 2011, UNESCO, 2016).

\subsection{Significant Threats}

The Ministry of Culture, Tourism \& Antiquities and the Department of Antiquities have been addressing the concerns of the World Heritage Committee, the World Heritage Centre of UNESCO, and the international experts from ICOMOS. A number of projects have been initiated, including an inventory system for displaced architectural elements including detached glazed tile and decorative stone. For some decorated stone individual tombs, a process of anastylosis has been undertaken. Rubbish bins have been distributed throughout the site to maintain a clean environment, nearly 200 trees have been planted to reduce the wind-borne sand and salts, and illegal businesses have been relocated off-site. All private cars have been banned, and a system of electric buses are available for visitors. A visitor plan and management plan are in process. A number of conservation emergency stabilization projects have been executed at the monuments of Jamia Masjid, Essa Khan II, and Mubarak Khan. An initial documentation effort was undertaken including an initial inventory of the tombs with photography and drawings with drone photography. One important element of the documentation project is an accurate topographic survey in a Computer-Aided Drawing model that will form the base for a future Geographic Information System (Eppich, 2018). UNESCO Pakistan has also undertaken limited laser scanning. An inventory of the remaining glazed tile in situ was conducted by the non-profit Heritage Foundation Pakistan including photography of the remaining tile. However, one of the most significant threats is unstable geology and erosion as the site is located at the eastern edge of ancient bluffs. The subsidence and deficient soil characteristics are the cause of differential settlement and thus structural problem at a number of major tombs. The subsurface strata are composed of stone, decomposed stone, and layers of fine silt which when exposed at the edge of the bluff erode and provide insufficient bearing capacity resulting in vertical and horizontal movement (Beckh, 2018). Therefore, it became necessary to monitor movement.

\subsection{Approach}

It was essential that the monitoring documentation requires limited training and function cost-effectively given the extensive number of monuments with limited staff and budget. It was also important that precision was correlated with the significance of the monument and risk. Numerous cracks with varying dimensions were encountered, both parallel and perpendicular, in monuments at proximity to the head of the bluffs. Some cracks had been monitored in the past with plaster or glass tell-tales, but all were undocumented, undated, broken with some showing signs of movement. The wide variety of monuments from different periods from the $\mathrm{XIV}^{\text {th }}$ to XVIII ${ }^{\text {th }}$ centuries, along with a diversity of masonry construction techniques, location near the slope, risk levels, and degrees of significance provided a unique opportunity to create a protocol and utilize a wide variety of low-cost as well as more accurate methods.

\footnotetext{
* Corresponding author
} 


\section{MONITORING MOVEMENT}

\subsection{Methodology}

Although the problems of the underlying geology and movement of the monuments were known for decades, there had been no systematic monitoring of the situation. Therefore, there was no system in place or data to analyze movement over time or the severity of movement. The first step was to design a monitoring protocol and methodology. This methodology began with a review of all previous documentation at the archive in Karachi. This revealed a valuable source of historic photographs. In addition, a number of historic photographs were discovered within the on-site archive which was subsequently scanned and cataloged. These historic photographs from the beginning of the $\mathrm{XX}^{\text {th }}$ century provided valuable information as most were dated and of high resolution from a large format camera. Cracks could be detected as well as a number of historic interventions, mostly executed during the British Period to prevent movement. There were also a number of glass and plaster crack monitors discovered on site, but there were absolutely no written records uncovered. Also, these existing crack monitors did not have any dates or other information recorded in situ on the plaster. This was unfortunate as many of these crack monitors showed some signs of minor movement, but it was unknown when the movement occurred or the magnitude of the movement. The second step included a rapid assessment of all tombs within the site. This was a significant undertaking that required approximately six months, given the sheer size of the site. Following this, a matrix of the tombs, their condition, location in proximity to the slope, presence of cracks, and, critically, the level of significance was developed. This allowed the site manager and his team to prioritize the monuments and address the most serious concerns. The third step was to allocate a system for crack monitoring for each monument and design an inspection protocol.

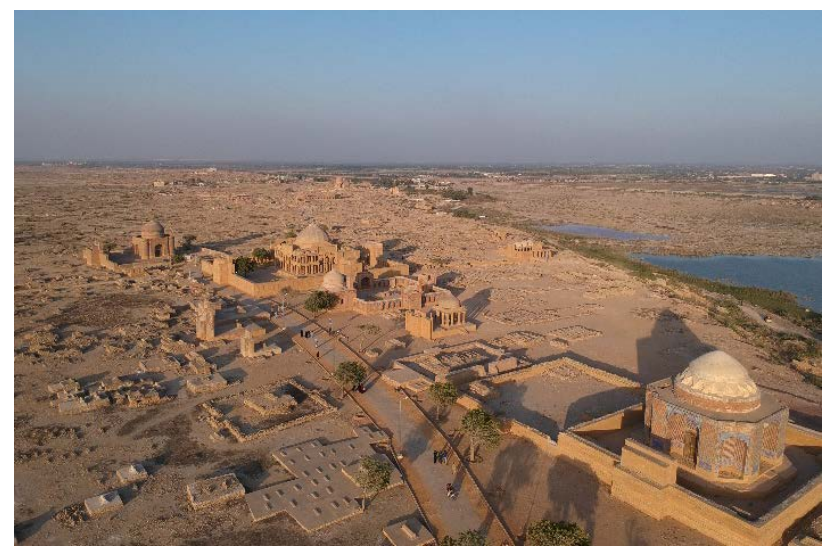

Figure 1. Overall view of the first cluster of structures at the south of Makli. The site extends for six kilometers to the north.

\subsection{Geological, Engineering Review}

In addition to the archival research and on-site inspection, a review of past geological investigations and projects was undertaken. One such project was undertaken by the Heritage Foundation Pakistan in 2011 around the significant monument of Jam Nizam Al Din. These investigations proved extremely useful, particularly the crack inspections, detailed condition assessment, drawings, and section 13 on the underlying the geology.
As a part of this project, a detailed subsoil study was undertaken by Consolidated Engineering Services to investigate the prevalent conditions. Three boreholes were drilled up to a depth of 15 meters utilizing rotary drilling methods. Standard tests were conducted, and laboratory tests concluded that sand and clay with gravel and cobble deposits were found in the topsoil. "This gave way to silty Shale compressed between two layers of sandy and nodular Limestone followed by nodular Sandstone. The physical characteristics determined that the shale lacked cementation or cohesion and when exposed to the atmosphere degraded. Among the findings listed the Geotechnical engineer assessed that the tomb at the time of construction might have been further away from the edge of the slope, and due to the constant weathering and erosion of the shale and the consequent collapse of the top layer of limestone has caused the settlement of the structure. Recommendations included the use to 'crack monitors’ or tell-tales” (Heritage Foundation, 2011, p 81)

Another critical investigation was conducted in early 2018 by engineer Dr. Matthias Beckh. This report also focused on Jam Nizam Al Din but, importantly, included investigations into the type of construction, the geology, and other structures suffering from the same conditions. In his report, Beckh states, "the ongoing erosion of the cliff exacerbates the situation and accelerates the deterioration of the monument. In order to safeguard the monument, it is essential to improve the soil characteristics of the subsoil and to contain the lateral movement of the deeper strata of fine silt” (Beckh, 2018, p 3). The report goes on to state in the recommendations that highprecision crack meters should be installed at various locations of the structure to monitor the movement of the tomb more accurately and that all crack meters need to be monitored and recorded at least once per month with photography (ibid, p 10).

\subsection{Protocol}

After archival and on-site review and taking into account the previously mentioned studies, three different methods were chosen to monitor movement at the tombs at Makli. Each has its advantages and disadvantages, including cost, time to monitor, and accuracy. 1) Regular detailed inspection with possible installation of simple plaster crack monitors, 2) installation of polycarbonate crack monitors installed in strategic locations and important monument of lower risk and 3) digital crack monitors at Jam Nizam Al Din, one of the most significant structures at high risk located at the very edge of the slope.

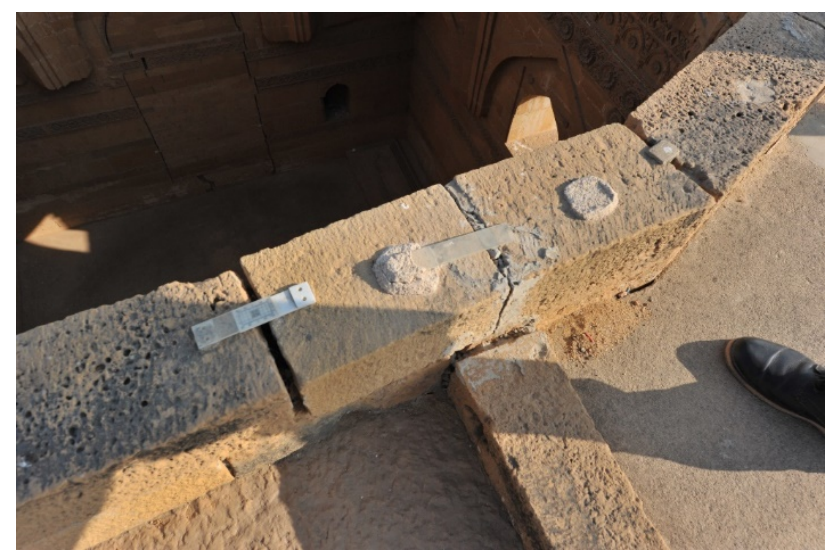

Figure 2. Old plaster and glass crack monitors were discovered on several monuments, but there were no written records 
For the least significant monuments at the lowest risk level, simple but regular on-site observations with digital calipers and plaster crack monitors were determined to be sufficient and the most cost-effective. This method is accurate to $1-2 \mathrm{~mm}$ and should any movement be detected, or suspected; then the monument would be upgraded to the second method. This category also included recently addressed monuments that underwent emergency stabilization. Although these structures underwent assessment and interventions including addressing foundation and movement issues, it was not assumed they would be stable and thus continued monitoring was necessary but at the lowest level.

For the more significant monuments at a higher risk level and closer to the head of the slope, polycarbonate two-piece crack monitors (Avonguard type) with an accuracy of 0.3 millimeters were installed in various critical specific locations both perpendicular and parallel to the slope. These were installed at five major monuments in January 2017 by the Department of Antiquities. Fifteen crack monitors were installed at five significant monuments at Makli including the mausoleums of Jam Nizamuddin, Deewan Shurfa Khan, Issa Khan Tarkahn-II, Mirza Jani Baig and Tughral Baig.

These five monuments were determined to have some historic movement and were of medium to high significance. Plaster or glass crack monitors had been installed in the past, and this also provided an indication that that demonstrated some movement had occurred. These plastic crack monitors cost between 20-30 euros each plus time for installation thus were only used at the more significant monuments. The design of this protocol is that initially, the crack monitors were to be inspected bi-weekly by observation, digital calipers, and photography. This would be entered into a log book. Should no movement be detected, then the inspection would be reduced to once per month. Should any movement be detected, the frequency of inspection would increase, additional crack monitors installed and more accurate digital crack monitors will be considered. These crack monitors were installed with UV resistant silicon which with solvent could be easily removed. Screws and epoxy were not used in the original masonry unless deemed absolutely necessary.

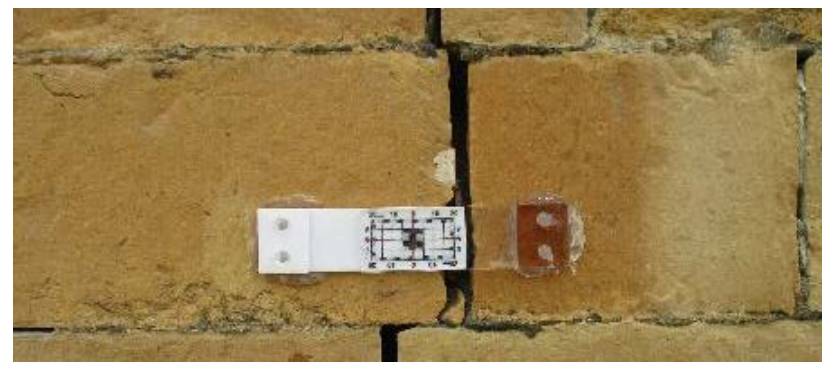

Figure 3. Installation of polycarbonate crack monitors

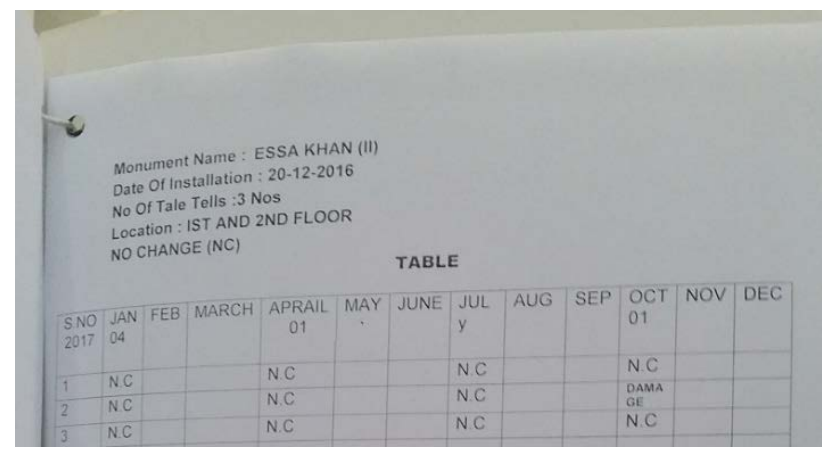

Figure 4. Logbook showing no changes after the inspection

\subsection{Jam Nizam Al Din}

At the highly significant tomb of Jam Nizam Al Din, a more precise method of monitoring movement was required. This tomb is at high risk at the very head of the slope, and various structural intervention attempts were made over the last century to halt movement. These past interventions included a massive concrete slab between the monument and the head of the slope, large masonry infills within the lower historic openings, grouting, and filling of large 20-30 cracks in the mortar joints. It was known from the archival photographs and research that many of these interventions and the historic openings had been closed in the early XXth century during the British Period. In addition, limited crack monitoring had taken place with glass tell-tales and plaster monitors. However, this monitoring was insufficiently documented, undated, and several monitors were broken. Twelve plastic crack monitors were installed as per the previously mentioned process, both parallel and perpendicular to the slope in both the vertical and horizontal directions. One of the monitors installed during the initial phase of this process showed a movement of $1.0 \mathrm{~mm}$.

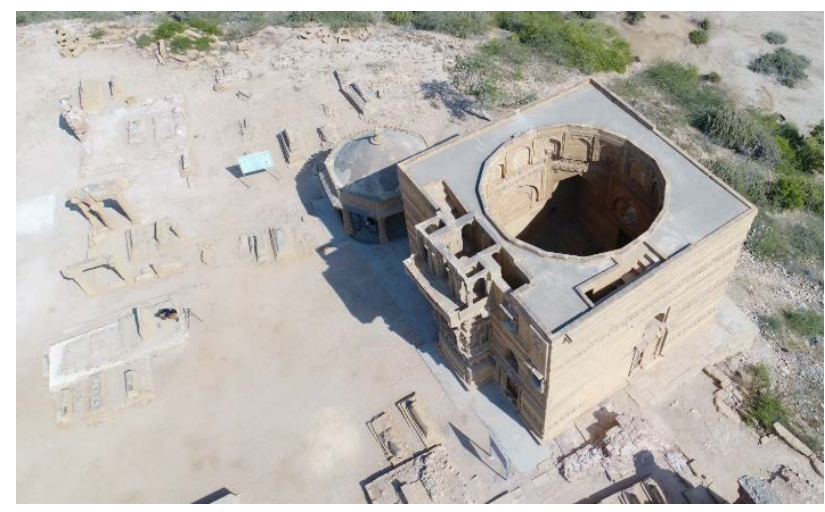

Figure 5. The highly significant tomb of Jam Nizam Al Din at the north end of the Makli Hills, World Heritage property

To enhance the monitoring of the movement, a highly sensitive digital crack monitor (Rissfox Datenlogger Scanntronik Magrauer with Softfox) was installed. This crack monitor is sensitive to $0.0026 \mathrm{~mm}$, and during a test installation, it was observed that the monument expanded and contracted by over $0.4 \mathrm{~mm}$ due to daily temperature changes. Due to the high cost of this method, only one monitor was installed at the point of highest bending moment at the roof masonry at the furthest point from the foundations. Also, due to the high cost, only one digital crack monitor was installed. Should any movement be detected, additional digital crack monitors can be installed and networked together along with temperature and humidity sensors. Training in installation and operation of this digital crack monitor was included in this process as well as a continued monitoring protocol and use of the software. One important aspect of this installation was real-time monitoring. Should interventions take place on or near the monument, such as the drilling of additional exploratory geological boreholes, or intervention such as micro-pilings or other conservation measures, the on-site conservation team are able to monitor any movement in real-time and be able to stop all work once a certain tolerance of movement has been detected. Other highly sensitive instruments for monitoring movement were considered such as a vibrating wire crack monitor but these were prohibitively expensive, and the accuracy of the selected instrument was deemed adequate. 


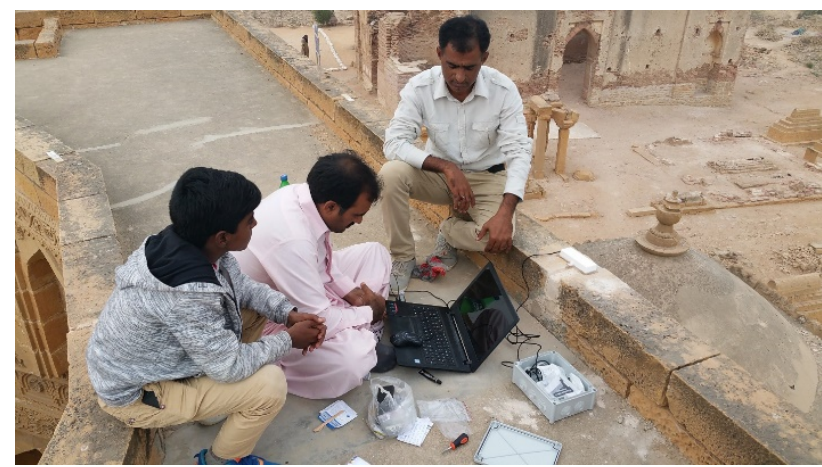

Figure 6. The team installing the digital crack monitor, 2019

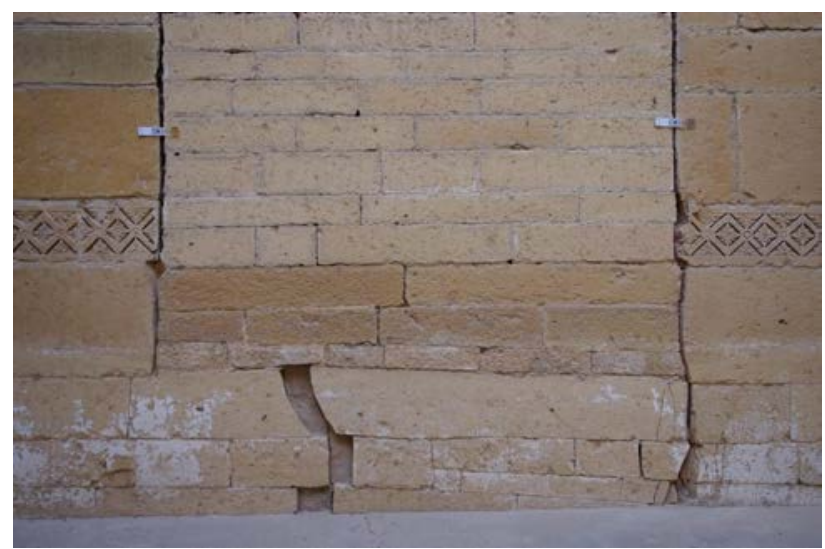

Figure 7. large cracks between the masonry infill and the original structure, 2018

\subsection{Meteorological Data}

One important aspect of monitoring the movement at the tomb of Jam Nizam Al Din with highly accurate instrumentation is the correlation of the crack monitoring data with temperature. This is necessary to determine if the movement is due to temperature changes. Fortunately, the site management installed a meteorological station very close to the tomb. In 2018, a meteorological report was conducted by Nadeem Faisal \& Asif Hussain, PMD. The data for the period 10th November 2017 to 12 November 2018 was assessed, and the monitoring is ongoing. The data at Jam Nizam site was processed, and a box plot for extreme and average temperature for the site is depicted below. The bottom whisker indicates the lowest temperature while an upper whisker indicates the highest maximum temperatures of each month. The upper \& bottom parts of the boxes are representing the average maximum, and minimum values and small size of black dotted lines in boxes are the average temperature values of each month (Faisal, 2018). This data is being correlated with the crack monitoring data. An integrated temperature system inside the crack monitor was investigated but deemed unnecessary as the weather had already been installed nearby and was functioning adequately.

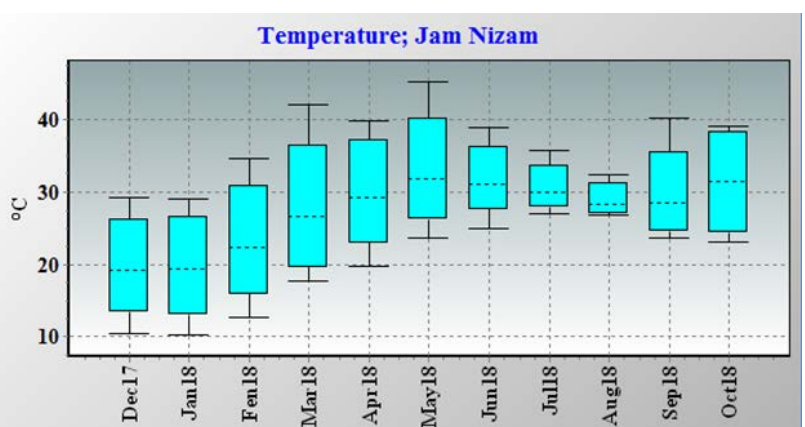

Figure 8. Box plot for the temperature of Jam Nizam site

\section{FINDINGS}

Although the crack monitoring protocol has only been in place since early 2018, it has yielded some initial results. The first category of monuments has shown no movement, and thus, additional monitoring was not deemed necessary. In addition, several of these monuments underwent emergency consolidation later in the year.

The second category of monuments revealed that no movement is occurring; thus, the inspections were reduced to once per month. Even though there was no movement detected it had been stressed by the site manager that vigilance must remain high and the conservation team must be ready to increase monitoring protocol should any change be detected or an external event such as an earthquake or heavy monsoon.

The final category of more accurate monitoring at Jam Nizam Al Din has, over the ten months of monitoring revealed no significant structural movements. The main north-south crack that is parallel to the head of the slope expands and contracts daily with temperature fluctuations of between $0,061+\mathrm{mm}$ and $0,042-\mathrm{mm}$. Nevertheless, the team is monitoring the situation on a monthly basis and continues to study the data. Should an earthquake, heavy rain, or monsoon occur, the team will immediately check the data. This process has resulted in a better knowledge of the movement and nature of the structure and prepares the site management for a more in-depth study in preparation for intervention.

The approach used to monitor a large number of monuments a Makli was pragmatic given the staff and budget limitations. The team developed a method to identify, inventory, and categorize the cracks, establish a risk level that was correlated with the significance of the monument. This approach allowed the site manager to priorities for monitoring and intervention. The monitoring protocol, method, appropriateness, accuracy, and cost-effectiveness utilizing three different types of monitors are appropriate and cost-effective. The protocol described attention to decisions to improve the accuracy and frequency of the recording should any movement be detected or should a seismic or weather event occur. 


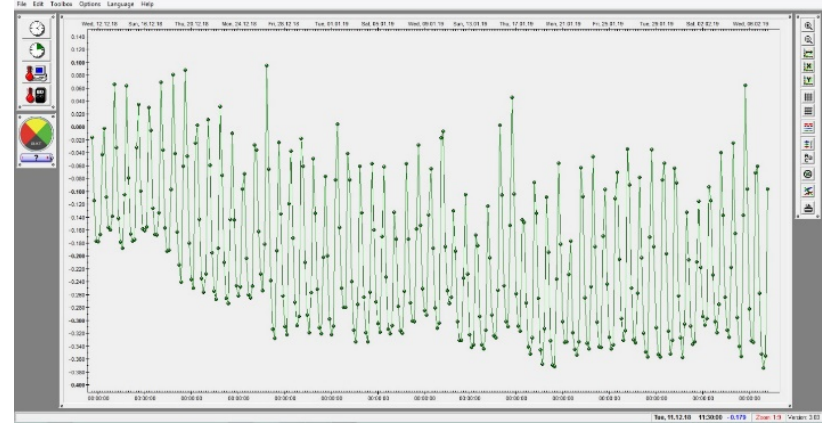

Figure 9. Digital crack monitor results showing the daily movement of $0,061+\mathrm{mm}$ and $0,042-\mathrm{mm}$ due to thermal expansion

\subsection{Conclusions}

The recent findings show that while there have no significant movements in the last ten months, nevertheless the site manager and his team remain vigilant and will continue to monitor the structures of Makli for movement. This monitoring system has only just been implemented and must be continued and expanded. Additional crack monitors, including the more accurate digital crack monitors, can be installed and the training will continue. In addition, research into measuring the cracks from the historic photography will be undertaken to utilize photogrammetry. This research may give the team an indication of the rate of change. This initial phase of the monitoring system and the more accurate monitoring at Jam Nizam Al Din and will serve useful once a sensitive structural intervention is designed. The monitoring of the movements only better informs conservation decisions and implementation design.

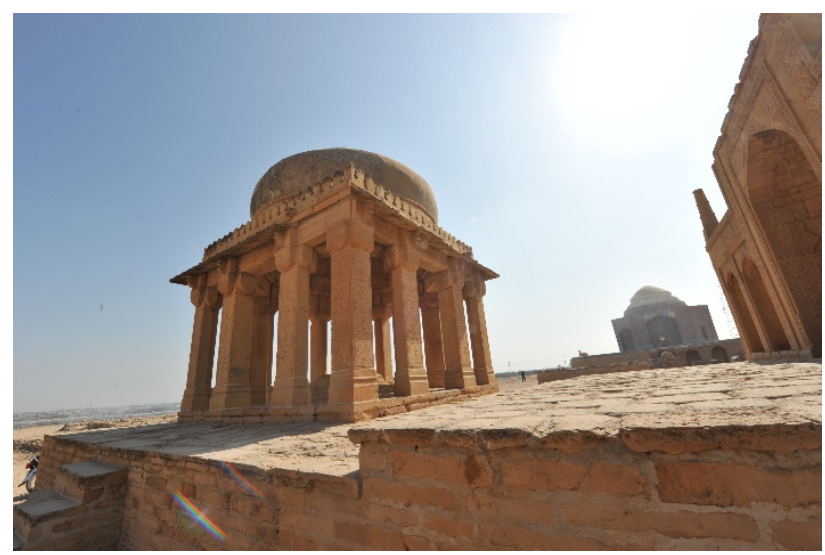

Figure 10. A canopy tomb near the southern extreme of the site.

\section{ACKNOWLEDGMENTS}

Acknowledgments for the monitoring program must be made as it is not the work of the authors but of the entire team from the Sindh Government. This includes the Minister of Culture, Tourism\& Antiquities, the honorable, Sardar Ali Shah; the Secretary Culture, Tourism \& Antiquities Department, Mr. Ghulam Akbar Laghari and Director General Manzoor Kanasro of the Antiquities Department. Special thanks must be given to Junhi Han, Programme Specialist, UNESCO, World Heritage Centre. Thanks must also be given to the numerous individuals from the World Heritage Centre and ICOMOS that visited the site and offered their advice over the last several years, including the Reactive Monitoring Missions. This advice provided fertile ground for real improvements on site in both conservation and management.

\section{REFERENCES}

Beckh, M., 2018. Tomb of Jam Nizam Al Din Makli World Heritage Site Province of Sindh - Islamic Republic of Pakistan, Structural Damage assessment and recommended consolidation measures Structural Engineering and Conservation, unpublished, München / Zürich.

Eppich, R., 2018. International Perspective on Recent Conservation Efforts at Makli, Sindh Antiquities, Quarterly Journal Vol. 1, no. 4. Special Edition, Makli International Conference, General Directorate of Antiquities and Archaeology, Sindh, Karachi.

Faisal, N., Hussain, A. 2018 Weather monitoring report, provided to the Sindh Government, unpublished, Karachi.

Heritage Foundation of Pakistan, 2011. The Tomb of Jam Nizam al-Din Documentation \& Condition Survey, Heritage Foundation Pakistan, Karachi.

Khan, A., Nabi, and Wheeler, R., 1989. Islamic Architecture in South Asia. Oxford: Oxford University Press, Oxford.

Lari, Y., Mihail, S., 1997. The Jewel of Sindh, Samma Monuments on Makli Hills, Karachi, Heritage Foundation Oxford University Press, Heritage Foundation Pakistan, Oxford.

Lari, Y., 1999. Traditional Architecture of Thatta, Heritage Foundation Pakistan, Karachi.

Nadiem, I.H., 1963. Makli, The Necropolis at Thatta. Sang-eMeel Publications, Rajput, A. B. Architecture in Pakistan. Karachi: Pakistan Publications, Lahore.

Qasim, A., 2011. Makli Hills Monument Thatta: History, Architecture, Conservation, Journal of Research in Architecture and Planning: Vol. 16, 2014 (First Issue) Restoration of the Tomb of Samma Noble I, Makli Necropolis, Thatta, Pakistan. Preventing the further degradation of a World Heritage site, Prince Claus Fund, Amsterdam.

Siddiqi, M.I., 1963. Makli: Thatta, Department of Archaeology in Pakistan, Karachi.

Siddiqi, M.I., 1970. Makli, The Quarterly Archaeology, Vol: XIX No. 1 January Thatta, Department of Archaeology\& Museums, Ministry of Education \& Scientific Research, Government of Pakistan, Karachi.

UNESCO, World Heritage Centre/ICOMOS, 2016. Reactive Monitoring Mission to the World Heritage property "the Historical Monuments at Makli, Thatta,” Pakistan, Paris.

UNESCO World Heritage Centre, 2006-2016. The Necropolis at Makli, Thatta, Reactive Monitoring Mission reports, Paris.

Zofeen, E., 2014. A New Life or Final Breath for the World's Greatest Necropolis? Mint Press News, Karachi. Accessed 2018. http://www.mintpressnews.com/a-new-life-or-a-finalbreath-for-worlds-largest-necropolis/197730/ 